\title{
Desempenho da cultura do arroz irrigado com esgotos sanitários previamente tratados
}

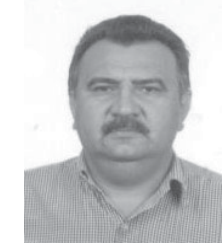

\author{
José T. de Sousa' ${ }^{1}$ Valderi D. Leite ${ }^{2} \&$ João G. de Luna ${ }^{3}$ \\ 1 Departamento de Química/UEPB. Rua Basílio Araújo 836, Catolé, CEP 58104-693, Campina Grande,PB. Fone (83) $337-1548$. \\ E-mail: jtavares@paqtc.rpp.br (Foto) \\ 2 Departamento de Química/UEPB. E-mail: valderi@paqtc.rpp.br \\ 3 Departamento de Matemática e Estatística/UEPB. E-mail: prodema@uepb.rpp.br
}

Protocolo $068-21 / 06 / 2000$

\begin{abstract}
Resumo: Com o presente trabalho, objetiva-se avaliar o desempenho da cultura do arroz, irrigada com efluentes de esgoto sanitário provenientes de tanque séptico e de lagoa de estabilização, tomando-se como referencial comparativo a mesma cultura irrigada com água de abastecimento em solos fertilizados com adubos minerais e sem adubo mineral. No experimento foi utilizada a cultivar Diamante, originada da EMBRAPA Meio Norte, e o sistema experimental era constituído por 4 tabuleiros com $10 \mathrm{~m}^{2}$ de área unitária, irrigados por inundação intermitente, procurando-se manter sempre uma média de $5 \mathrm{~cm}$ de lâmina líquida a cada dois dias, durante o período de 4 meses. A análise dos dados demonstra que a produtividade da cultivar Diamante, irrigada com efluente de tanque séptico, foi superior à produtividade da mesma cultivar irrigada com água de abastecimento em solo com adubação mineral. Salienta-se, ainda, que os grãos da cultivar irrigada com efluente do tanque séptico não apresentaram, em nenhum exame, indicadores de contaminação fecal.
\end{abstract}

Palavras-chave: tratamento anaeróbio, lagoa de estabilização, reúso de águas, Oryza sativa

\section{Performance of upland rice irrigated with previously treated domestic sewage}

\begin{abstract}
This paper evaluates the rice crop performance irrigated by domestic wastewater effluents from septic tanks and ponds in comparison to that irrigated by muncipal water supplies in soils with and without mineral fertilizers. The "Diamante" rice cultivar originated from EMBRAPA Meio Norte was used in the experiment. The experimental system consisted of 4 plots of $10 \mathrm{~m}^{2}$. The plots were intermitlenttly flooded every two days during the period of four months to maintain on an average $5 \mathrm{~cm}$ of water depth. The analytical data show that the productivity of the cultivar "Diamante" in this system was higher than that of the same cultivar irrigated by muncipal water supplies in soils with mineral fertilizers. Also when examined, its grains did not present any traces of fecal contamination.
\end{abstract}

Key words: domestic wastewater, stabilization pond, water reuse, Oryza sativa

\section{INTRODUÇÃO}

No semi-árido do Nordeste brasileiro, onde a precipitação pluviométrica anual varia de 300 a $800 \mathrm{~mm}$ de chuvas distribuídas geralmente durante o período de três meses, ocorre evapotranspiração excedente e as plantas sofrem déficit hídrico. Assim, a irrigação torna-se a prática mais segura para garantir a produção agrícola na região; no entanto, para suprir a demanda da água desta região, precisa-se não somente administrar racionalmente as bacias hidrográficas locais mas, também, implantar uma política racional, no sentido de se tratar convenientemente os esgotos sanitários provenientes dos grandes centros urbanos, objetivando-se reusá-los para fins de agricultura pois, além de suprir a água que é tão escassa na região serve, também, como fertirrigação orgânica vindo, assim, consubstanciar ações direcionadas para o desenvolvimento sustentável da região (Sousa et al.,1998).

Sabe-se que esgotos domésticos, quando reusados sem serem tratados, podem contaminar o ambiente com bactérias, parasitos e vírus criando, portanto, graves problemas de saúde pública, pois propagam doenças bacterianas e virulentas, afetando trabalhadores e consumidores das culturas irrigadas (Metcalf \& Eddy, 1991; Leon \& Cavallini, 1996). A água reusada na irrigação deve ter bons padrões de qualidade físico-químicos e sanitários. Desta forma, os principais constituintes que devem ser avaliados, são: os sais presentes na água e no solo, que reduzem a disponibilidade da água para a planta; as altas concentrações de sódio ou baixa de cálcio, que fazem diminuir a velocidade de infiltração da água; a toxicidade de íons específicos (sódio, cloreto e boro) e o excesso de nutrientes, além de organismos patogênicos (Sousa et al., 2000). 
Finalmente, as águas residuárias tratadas, quando lançadas em corpo d'água ou mesmo infiltradas no solo, sofrem naturalmente diluição e aeração podendo, assim, ser novamente captadas, tratadas e reutilizadas como água potável. A água doce do planeta é uma fonte renovável, do ponto de vista qualitativo e quantitativo, desde que haja planejamento e um gerenciamento cuidadoso e criterioso para tornar, assim, um ciclo sustentável.

O cultivo do arroz, difundido nacionalmente, é realizado, atualmente, com alta tecnologia exigindo, portanto, um intenso uso de insumos. A utilização excessiva de fertilizantes e herbicidas associados ao grande volume de água vem promovendo impactos ambientais negativos. Segundo Zaffaroni \& Tavares (1999) a evapotranspiração média do arroz irrigado por inundação varia de 6,7 a $7,7 \mathrm{~mm} \mathrm{~d}^{-1}$, em região de clima temperado. No semi-árido, devido a evapotranspiração ser um tanto maior tem-se, consequentemente, alta concentração de sais no solo, contaminando o lençol freático; já o excessivo uso de fertilizantes químicos e pesticida tem contaminado a água, o solo e o ar, resultando em danos à saúde do ser humano e perda da biodiversidade.

Dentre os cereais, o arroz é uma cultura de grande importância na dieta alimentar do povo brasileiro. Quase todos os Estados brasileiros produzem este cereal. Segundo a EMBRAPA (1996) o Brasil precisa aumentar sua produção de arroz em $3,3 \%$, até o ano 2000 para, assim, atender ao crescimento da taxa populacional, de $1,7 \%$ ao ano. Para se obter maior produtividade, tem-se diversos fatores, entre eles: melhoramento genético da planta, controle de pragas e doenças, manejo de água, planta e solo, e muitos outros, destacando-se a nutrição mineral de plantas, tendo em vista que, sem esta, todas as outras contribuições teriam pouco sentido. Portanto, utilizando-se esgotos sanitários tratados, tem-se nutrientes como: nitrogênio, fósforo, enxofre, cálcio e magnésio, que as plantas podem utilizar, tornando desnecessário a aplicação de adubação mineral.

O objetivo do trabalho foi avaliar o desempenho da cultura do arroz irrigado, com esgotos sanitários pré-tratados anaerobiamente e pós-tratados em lagoa de estabilização, além de comparar a produtividade do arroz produzido com esgotos tratados com a produtividade do arroz irrigado com água de abastecimento.

\section{MATERIAL E MÉTODOS}

O estudo foi realizado no Centro de Pesquisa, pertencente à Companhia de Água e Esgotos do Estado da Paraíba (CAGEPA), vinculada à Universidade Federal da Paraíba, no município de Campina Grande. Para tanto, foram construídos quatro tabuleiros de $10 \mathrm{~m}^{2}$ cada um $(10,00 \times 1,00 \mathrm{~m})$ de alvenaria e revestidos internamente com massa impermeabilizante; depois, foram divididos internamente em unidades experimentais de $2 \mathrm{~m}^{2}$. Utilizaram-se três plantas por cova, com

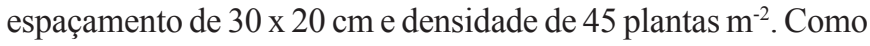
planta indicadora foi utilizado o arroz (Oryza sativa L.) cultivar Diamante, irrigada, proveniente da EMBRAPA-PI.

$\mathrm{O}$ experimento foi instalado num delineamento inteiramente casualizado, considerando-se quatro tratamentos, com cinco repetições. Os tratamentos utilizados foram caracterizados conforme descrição a seguir. T1: irrigado com esgotos pré-tratados, em tanque séptico; T2: irrigado com esgotos pré-tratados, em tanque séptico e, em seguida, exposto em lagoas de maturação; T3: irrigado com água de abastecimento e T4: adubação recomendada pela análise de solo: $\left(10 \mathrm{~kg} \mathrm{ha}^{-1}\right.$ de N, $60 \mathrm{~kg} \mathrm{ha}^{-1}$ de $\mathrm{P}_{2} \mathrm{O}_{5}$ e $60 \mathrm{~kg} \mathrm{ha}^{-1}$ de $\mathrm{K}_{2} \mathrm{O}$ ). Após 20 e 60 dias, respectivamente, foi efetuada adubação de cobertura com $40 \mathrm{~kg}$ de N.ha' ${ }^{-1}$, na forma de sulfato de amônia (EMBRAPA, 1996) sendo irrigado com água de abastecimento. A irrigação nas vinte unidades experimentais foi efetuada por inundação intermitente, mantendo-se uma lâmina média de $5 \mathrm{~cm}$ a cada dois dias.

As análises estatísticas foram conduzidas segundo metodologia proposta por Gomes (1985); neste sentido, as variáveis consideradas no estudo foram: NUMPANIC: número de panícula; MAS100: massa de 100 grãos (g); GRAPANIC: número de grãos por panícula; PROD: produtividade em quilograma por hectare; RQPROD: raiz quadrada da produtividade.

As variáveis analisadas durante todo o monitoramento, foram: temperatura, $\mathrm{pH}$, condutividade elétrica, demanda química de oxigênio (DQO), nitrogênio amoniacal, nitrogênio total Kjedahl e fósforo total. Com exceção das três primeiras determinações, as demais seguiram métodos de análise descritos pelo APHA (1995). As amostras bacteriológicas foram processadas em duplicata, com base em recomendação do APHA (1995). A contagem de coliformes fecais foi realizada utilizando-se a técnica de filtração em membrana, com incubação a $44,5^{\circ} \mathrm{C}$, durante $24 \mathrm{~h}$. O meio de cultura utilizado foi m-FC (DIFCO) e o indicador foi ácido rosálico. Os resultados foram expressos em Unidade Formadora de Colônia (UFC) por $100 \mathrm{~mL}$.

\section{RESULTADOS E DISCUSSÃO}

A adequação da água para irrigação é um tanto subjetiva, mas se deve avaliar alguns parâmetros que poderão produzir efeitos desagradáveis na relação água, planta e solo. Uma água pode ser considerada adequada para certo tipo de solo ou cultura, porém inadequada para outros. Para tanto, deve-se analisar as características físico-químicas, a qualidade sanitária da água e as características do solo, a tolerância das culturas a serem utilizadas, o clima local, o manejo da irrigação e a drenagem (Holanda \& Amorim, 1997).

$\mathrm{Na}$ Tabela 1 são apresentados os principais dados estatísticos dos parâmetros físico-químicos dos efluentes do tanque séptico e da lagoa de maturação.

Os efluentes provenientes do tratamento anaeróbio e da lagoa de estabilização, utilizados na irrigação da cultura do arroz, apresentavam concentração ainda considerável de coliformes fecais $\left(10^{7}\right.$ a $\left.10^{5} \mathrm{UFC} 100 \mathrm{~mL}^{-1}\right)$ respectivamente, bem superior, portanto, aos padrões recomendados pelo WHO (1989) e CONAMA no 20 (1986); no entanto, o arroz produzido não apresentava indicadores de coliformes fecais, enquanto os parâmetros físico-químicos apresentados na Tabela 1, exceto nutrientes, estão numa faixa de segurança recomendada para irrigação. Os valores apresentados na Tabela 1, com exceção dos coliformes fecais, são similares àqueles apresentados por Vazquez-Montiel et al. (1996) quando reusavam esgotos domésticos para irrigação. 
Tabela 1. Características do efluente do tanque séptico e lagoa de estabilização utilizado na irrigação do arroz

\begin{tabular}{|c|c|c|c|c|c|c|c|}
\hline \multirow{2}{*}{ Parâmetros ${ }^{*} /$ Unidade } & \multirow[t]{2}{*}{$\mathrm{n}$} & \multicolumn{3}{|c|}{ Lagoa de Maturação } & \multicolumn{3}{|c|}{ Tanque Séptico } \\
\hline & & $\overline{\mathrm{x}}$ & $\delta$ & CV $(\%)$ & $\overline{\mathrm{x}}$ & $\delta$ & $\mathrm{CV}(\%)$ \\
\hline $\mathrm{DQO}\left(\mathrm{mg} \mathrm{L}^{-1}\right)$ & 18 & 229,0 & 56,0 & 25,0 & 428,0 & 173,0 & 40,0 \\
\hline $\mathrm{DBO}_{5}\left(\mathrm{mg} \mathrm{L}^{-1}\right)$ & 15 & 80,0 & 45,0 & 56,0 & 155,0 & 69,0 & 45,0 \\
\hline $\operatorname{SST}\left(\mathrm{mg} \mathrm{L}^{-1}\right)$ & 15 & 101,0 & 39,0 & 40,0 & 162,0 & 74,0 & 48,0 \\
\hline Fósforo Total $\left(\mathrm{mg} \mathrm{P} \mathrm{L}^{-1}\right)$ & 19 & 6,60 & 1,7 & 250 & 7,4 & 1,3 & 25,0 \\
\hline NTK (mg N L $\left.{ }^{-1}\right)$ & 17 & 57,0 & 5,5 & 9,6 & 67,5 & 15,0 & 22,0 \\
\hline $\mathrm{N}-\mathrm{NH}_{4}\left(\mathrm{mg} \mathrm{N} \mathrm{L}^{-1}\right)$ & 17 & 37,0 & 7,2 & 19,0 & 56,0 & 11,0 & 20,0 \\
\hline Coliformes Fecais (UFC $100 \mathrm{~mL}^{-1}$ ) & 15 & $6,3 \times 10^{5}$ & - & - & $1,0 \times 10^{7}$ & - & - \\
\hline
\end{tabular}

"DQO: Demanda Química de Oxigênio; $\mathrm{DQO}_{5}$ : Demanda Bioquímica de Oxigênio, determinada com cinco dias de incubação a $20{ }^{\circ} \mathrm{C}$; SST: Sólidos Suspensos Totais; NTK: Concentração de Nitrogênio Total, determinado pelo método Kjedahl; $\mathrm{N}_{-} \mathrm{NH}_{4}{ }^{+}$: Concentração de nitrogênio com o íon amônio; UFC: Unidades Formadoras de Colônia; n: Número de determinação; x: Valor Médio; $\delta$ : Desvio padrão; CV: Coeficiente de Variação

A cultura do arroz exige consideráveis teores de nutrientes do solo, fato que faz com que a fertilidade natural do solo e/ou a aplicação de adubos, seja insuficiente para manter esta necessidade por muito tempo. Por outro lado, os nutrientes devem ser repostos ao solo através de adubação. Portanto, o reúso das águas residuárias domésticas que dispõem de micros e macronutrientes funciona como fertirrigação.

Os efluentes dos esgotos tratados utilizados na irrigação continham, segundo Metcalf \& Eddy (1991) altas concentrações

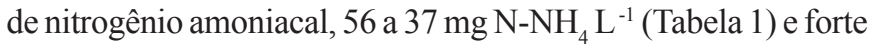
concentração de matéria orgânica ( $428 \mathrm{mg} \mathrm{L}^{-1}$ de DQO e $155 \mathrm{mg} \mathrm{L}^{-1}$ de $\mathrm{DBO}_{5}$ ). Quando o solo apresenta certa capacidade de armazenamento de nitrogênio (presença de matéria orgânica) pode parecer vantajoso utilizar-se, na irrigação, efluente contendo mais nitrogênio amoniacal que nitrogênio na forma de nitrato (Sousa et al., 1998). As plantas assimilam nitrogênio na forma de nitrato e na forma de íon amônio, porém, o nitrogênio presente em águas residuárias tratadas, quando reusadas na irrigação de culturas, pois tem o mesmo efeito do nitrogênio aplicado na forma de fertilizante.

Para a cultura do arroz, segundo Fageria et al. (2000) o nitrogênio é o nutriente limitante, seguido de fósforo e do potássio. O reuso de esgotos domésticos na agricultura evita a utilização de adubos minerais e, conseqüentemente, agrega no mínimo três vantagens: 1) dispensa fertilizantes minerais, 2) elimina a provável contaminação das águas subterrâneas e superficiais por fertilizantes, e 3) supre a escassez de água para fins domésticos.
Conforme se observa na Tabela 2 , houve efeito estatisticamente significativo para tratamento, a nível de 1 ou $5 \%$ de probabilidade, pelo teste $\mathrm{F}$, nas quatro variáveis estudadas.

No desdobramento dos graus de liberdade de tratamento em contrastes ortogonais de interesse, verificou-se que, em média, as respostas das variáveis estudadas aos tratamentos com esgotos pré-tratados anaerobiamente em fossa séptica, superaram os demais tratamentos. Por outro lado, as respostas das variáveis ao tratamento com esgotos pré-tratados não foram estatisticamente diferentes do tratamento com esgotos pós-tratados com lagoa de maturação. Também, as respostas das variáveis ao tratamento com água de abastecimento não diferiram do tratamento com água do abastecimento acrescido de adubo mineral indicando, assim, que a cultura não respondeu à adubação mineral aplicada.

Ainda de acordo com a Tabela 2, observaram-se maiores valores médios para as variáveis nos tratamentos $\mathrm{T} 1$ e $\mathrm{T} 2$, quando comparados aos valores médios nos tratamentos T3 e T4. No contraste das médias, duas a duas, pelo método de Tukey a $5 \%$ de significância, verificou-se que o número médio de panículas no tratamento $\mathrm{T} 1$ não diferiu estatisticamente do tratamento T2, nem T3 diferiu de T4. Por outro lado, tanto T1 quanto T2 diferiram de T3 e de T4. O valor médio da massa de 100 grãos no tratamento $\mathrm{T} 1$ apresentou diferença significativa, ao ser comparado com os tratamentos $\mathrm{T} 3$ e $\mathrm{T} 4$, sendo que os demais contrastes de médias nesta variável não foram significativos. Verificou-se, ainda, que o número médio de grãos

Tabela 2. Resumo de análise de variância, estimativas das médias dos tratamentos $\left(\mathrm{T}_{1} \mathrm{~T}_{2} \mathrm{~T}_{3}\right.$ e $\left.\mathrm{T}_{4}\right)$ número de panícula (NUMPANIC), massa de 100 grãos (MAS 100), número de grãos por panícula (GRAPANIC), raiz quadrada de produtividade (RQPROD) diferenças mínimas significativas (DMS) calculadas pelo método de Tukey a 5\% de significância e coeficientes de variação

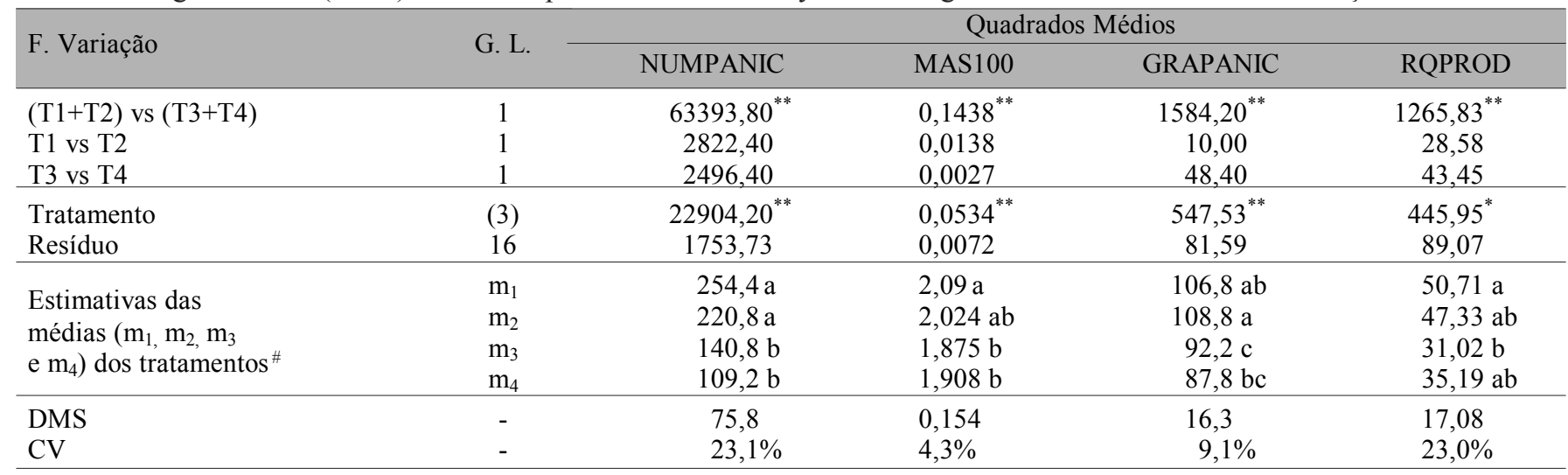

* e** Significativo a nível de 5 e $1 \%$ de probabilidade, respectivamente

* Médias seguidas da mesma letra não diferem significativamente, pelo método de Tukey, a $5 \%$ de probabilidade 
Tabela 3. Quadrados médios obtidos pela análise de variância, envolvendo um grupo de contrastes ortogonais de interesse

\begin{tabular}{|c|c|c|c|c|c|}
\hline \multirow{2}{*}{ F. Variação } & \multirow{2}{*}{ G. L. } & \multicolumn{4}{|c|}{ Quadrados Médios } \\
\hline & & NUMPANIC & MAS100 & GRAPANIC & RQPROD \\
\hline $\mathrm{T} 4$ vs $(\mathrm{T} 1+\mathrm{T} 2+\mathrm{T} 3)$ & 1 & $10935,00^{*}$ & 0,0313 & 299,27 & 229,80 \\
\hline $\mathrm{T} 3$ vs $(\mathrm{T} 1+\mathrm{T} 2)$ & 1 & $54955,20^{* *}$ & $0,1152^{* *}$ & $1333,33^{* *}$ & $1079,47^{* *}$ \\
\hline T1 vs T2 & 1 & 2822,40 & 0,0138 & 10,00 & 28,58 \\
\hline Tratamento & (3) & $22904,20^{* *}$ & $0,0534^{* *}$ & $547,53^{* *}$ & $445,95^{*}$ \\
\hline Resíduo & 16 & 1753,73 & 0,0072 & 81,59 & 89,07 \\
\hline
\end{tabular}

"Efeito estatístico significativo a nível de $5 \%$ de probabilidade, pelo teste $\mathrm{F}$

"* Efeito estatístico significativo a nível de $1 \%$ de probabilidade, pelo teste $\mathrm{F}$

por panícula no tratamento $\mathrm{T} 2$, superou o número médio de grãos por panícula nos tratamentos $\mathrm{T} 3$ e $\mathrm{T} 4$ e que a produtividade média no tratamento $\mathrm{T} 1$ apresentou diferença estatística significativa, ao ser comparada com a média do tratamento T3, não havendo diferença estatística para os demais contrastes de médias pelo método de Tukey, a 5\% de probabilidade.

De acordo com a Tabela 3, o número de panículas observado no tratamento T4 (água de abastecimento mais adubo mineral) diferiu da média dos demais tratamentos, a nível de $5 \%$ de significância, pelo teste $\mathrm{F}$; este contraste não apresentou significância estatística nas demais variáveis. Verificou-se, ainda que, em média, as respostas das quatro variáveis estudadas, ao tratamento com apenas água de abastecimento, foram inferiores às médias do tratamento com esgotos pré-tratados anaerobiamente, com limite de $1 \%$ de significância.

\section{CONCLUSÕES}

1. A produtividade média do arroz, observada nas unidades experimentais irrigadas com esgotos domésticos tratados anaerobiamente em tanque séptico, superou estatisticamente aquela observada nas unidades irrigadas com água de abastecimento e adubo mineral.

2. O número médio de panícula por metro quadrado das cinco repetições em cada um dos tratamentos mostra que o T1, irrigado com esgotos pré-tratados anaerobiamente em fossa séptica e o T2, irrigado com efluente de lagoa de maturação, produziram número de panículas maior que os $\mathrm{T} 3 \mathrm{e} \mathrm{T} 4$, ambos irrigados com água de abastecimento não adubado e adubado, respectivamente.

3. O arroz produzido com esgotos pré-tratados anaerobiamente e pós-tratado em lagoa de estabilização, depois de seco ao sol, não apresentou indicadores de coliformes fecais.

\section{LITERATURA CITADA}

APHA. Standard methods for the examination of water and wastewater. 15 ed. Washington, D.C.: American Public Health Association. American Water Works Association, Water Pollution Control Federation, 1995, 1134p.
Brasil. Leis, Decretos etc. Resolução CONAMA nº 20, de 18 de junho de 1986. In.: Diário Oficial da União. Distrito Federal, jul. 1986.

EMBRAPA - Empresa Brasileira de Pesquisa Agropecuária. Recomendações técnicas para o cultivo do arroz de sequeiro, Brasília: Embrapa - SPI, 1996, 31p.

Fageria, N.K.; Santos, A.B. dos; Zimmermann, F.J.P. Resposta do arroz irrigado à adubação residual e aos níveis de adubação em solo de várzea. Revista Brasileira de Engenharia Agrícola e Ambiental, Campina Grande, v.4, n.2, p.177-182, 2000.

Gomes, F.P. Curso de estatística experimental. 13 ed. Piracicaba, Nobel, 1990, 468p.

Holanda, J.S. de; Amorim, J.R.A. de. Qualidade da água para irrigação In.: Gheyi, H.R.; Queiroz, J.E.; Medeiros, J.F. (ed.) Manejo e controle da salinidade na agricultura irrigada. Campina Grande: UFPB/SBEA, 1997. p.137-169.

Léon, G.; Cavallini, J.M. Curso de tratamento y uso de águas residuales. Lima: OPS/CEPIS, 1996. 151p.

Metcalf \& Eddy. Inc. Wastewater engineering treatment disposal reuse. 3. ed. New York: McGraw - Hill, 1991. 1334p.

Sousa, J.T. de; Araújo, H.W.C. de; Catunda, P.F.C.; Florentino, E.R. Tratamento de esgotos sanitários por filtro lento, objetivando produzir efluente para reuso na agricultura, In: Simpósio Luso-Brasileiro de Engenharia Sanitária e Ambiental, 9, João Pessoa, PB, 1998, v.1, T.1, p.317-327, ABES, Rio de Janeiro, 1998.

Sousa, J.T. de; Leite, V.D.; Dantas, J.P.; Dionizio, J.A. Reuso de efluente de esgotos sanitários na cultura do arroz. In: Simpósio Luso-Brasileiro de Engenharia Sanitária e Ambiental, 9, Porto Seguro, Ba, 2000. p.1058-1063, ABES, Rio de Janeiro, 2000.

Vasquez-Montiel, O.; Horan, N.J.; Mara, D.D. Management of wastewater for reuse in irrigation. Water Science Technology, London, v.33, n.10-11, p.355-362,1996.

World Health Organization. Health guidelines for the use of wastewater in agriculture and aquaculture. Geneva: World Health and Organization, 72p. 1989. Technical Report Series. 778

Zaffaroni, E.; Tavares, V.E. O licenciamento at hbiental dos produtores de arroz irrigado no Rio Grande d Sul, Brasil. In.: Encontro das Águas, Paraguay. 1999. D sponível na Internet: www.iica.org.br/aguastrab 